\title{
Combined Approach of Vasodilators and Surgical Reconstruction in Diabetic Foot Ulcer: Experience in a Tertiary Care Hospital
}

\author{
Ibrahim $\mathrm{FB}^{\mathrm{a}}$, Islam $\mathrm{MR}^{\mathrm{b}}$, Akand $\mathrm{MM}^{\mathrm{c}}$, Anwar R ${ }^{\mathrm{d}}$, Anwar MA ${ }^{\mathrm{e}}$, Deb AK
}

\begin{abstract}
Background: Diabetic patients frequently suffer from chronic non-healing ulcer on the sole of foot as a result of combined peripheral neuropathy and arterial insufficiency. Many of them end up in amputation. The aim of this study was to see the outcome of diabetic patients presenting with ulcers that showed no signs of healing in sole of the foot for 3 months or more treated with combination of peripheral vasodilators and surgical reconstruction.

Methods: A cross sectional study of 249 patients who presented to Plastic surgery department in BIRDEM fromJanuary 2013 toDecember2015 was done. The patients who had existing associated chronic medical illness like Chronic Kidney Disease (CKD) requiring dialysis, malignancy, Status Asthmaticus and foot ulcer withWagner grade 4 and 5 and patients receiving drugs that cause immunosuppression like chemotherapeutic agents, steroids, and methotrexates were excluded from the study.
\end{abstract}

Results: All patients presented with non-healing ulcerations average size of which was $1.48 \mathrm{~cm}$ (range, 0.68 to $4 \mathrm{~cm}$ ) of more than 3 months in various parts of sole of the foot complicated by peripheral neuropathy and/or arterial insufficiency. After the use of peripheral vasodilators, these patients underwent a variety of surgical reconstructions such as simple skin graft, local flaps, regional flaps and distant flaps. In follow up of 3 to 36 months, 194 patients (77.91\%) achieved good results, 55(22.08\%) patients' required secondary procedure such as flap revision, debridement or Split thickness skin graft (STSG) due to post operative complications.

Conclusion: We conclude that chronic non-healing ulcers in diabetic patients can be successfully treated by combined approach of surgical reconstruction and peripheral vasodilators.

Keywords: Foot salvage, Peripheral neuropathy, peripheral vasodilator, Diabetic foot, Non healing ulcer, Ulcer sole of the foot.

(BIRDEM Med J 2018; 8(2): 108-113)

Author Information

a. Dr. Farzana B Ibrahim, Registrar, Plastic Surgery Unit, room1119, BIRDEM General Hospital, Dhaka

b. Dr. Mohammed Rashedul Islam, Assistant Professor, Plastic Surgery Unit, room-1119, BIRDEM General Hospital, Dhaka

c. Dr. Md. MorshedUddinAkand, Senior Medical Officer, Plastic Surgery Unit, room-1119, BIRDEM General Hospital, Dhaka

d. Dr. Raihan Anwar, Senior Medical Officer, Plastic Surgery Unit, room-1119, BIRDEM General Hospital, Dhaka

e. Dr. Md. Anwarul Islam, Senior medical Officer, Plastic Surgery Unit, room-1119, BIRDEM General Hospital, Dhaka

f. Prof. Brig. Gen. (Retd) Anjan Kumar Deb, Honorary Consultant, Plastic Surgery Unit, room-1119, BIRDEM General Hospital, Dhaka

Address for Correspondence: Dr. Farzana Bilquis Ibrahim, Registrar, Plastic Surgery Unit, room-1119, BIRDEM General Hospital, 122 KaziNazrul Islam Avenue, Dhaka, ibrahimfarzana @hotmail.com

Received: December 20, 2017

Accepted: February 28, 2018

\section{Introduction}

Diabetes mellitus is a fast-growing epidemic disease. ${ }^{1}$ Globally, its radical increase has resulted in an inevitable rise in diabetes related complications. Approximately 366 million adults are suffering from this disease according to a statistics in 2011 and the projected figure who are to be suffering from DM by 2030 is 9552 million. $^{2}$ Unfortunately, $20-30 \%$ of total healthcare resources are spent on this disease and to one of its vigorous complications named diabetic foot. ${ }^{3}$ More than 85 percent of major amputations in diabetic foot patients are proceeded by foot ulceration. ${ }^{4}$ This mutilating surgery can be minimized by multidisciplinary approach.

Diabetic foot is a term for foot problems in patients with diabetes mellitus (DM) because of arterial 
abnormalities and diabetic neuropathy, as well as a tendency toward delayed wound healing, infection, or gangrene of the foot. ${ }^{5}$ Foot ulcer is a disabling complication and not uncommon among patients with $\mathrm{DM}$. The disability and possible progression to the loss (amputation) of digits and limbs make it a serious issue. ${ }^{6}$

In 1989, the Saint Vincent Declaration marked a vital step with the aim to reduce the incidence of lower extremity amputations improving the healthcare measures for diabetic foot complications. ${ }^{7}$ By this time, it was documented that a progressive reduction of amputations rate for major amputationswas possible whereas the same wasnot true for minor amputations $(30.7 \%$ vs $4.6 \%){ }^{8}$

Peripheral Arterial Disease (PAD) is an independent risk factor for subsequent ulceration and limb loss in DM. It is present in $50 \%$ cases with diabetic foot ulceration (DFU). ${ }^{9}$ In diabetic people, the risk of PAD increases with age, duration of diabetes and presence of peripheral neuropathy.

There are several pharmaceutical agents like Pentoxifylline, Cilostazol, Aspirin and Clopidogrel that can be used to treat co-existing PAD in DFU. ${ }^{10}$ Among them Pentoxifylline is a hemorheologic agent whereas cilostazol is an oral phosphodiesterase type III inhibitor. The latter one is contraindicatedin case of heart failure patients. Cilostazol was found better functioning than Pentoxifyllinein Peripheral arterial disease.

The aim of this study was to observe the outcome of the treatment by a combined approach of vasodilators and surgical reconstruction in diabetic patients with non healing ulcer in the sole of the foot.

\section{Methods}

This longitudinal cross sectional study was conducted in the Department of Plastic and Reconstructive Surgery of BIRDEM General Hospital from January, 2013 to December, 2015. Initially 256 patients were selected according to purposive sampling. The selected patients were scrutinized by eligibility criteriawhich was having a non healing ulcer for more than 3 months in the sole of the foot and 249 patients were finalized to be selected in the study. The patients who had concomitant chronic medical illness like CKD requiring dialysis, malignancy, status asthmaticus and Wagner grade 4 and 5 were excluded from the study. Besides those who were receiving drugs that cause immunosuppression like chemotherapeutic agents, steroids, methotrexates were also excluded from the study.

The sole was divided into 8 different pressure zonesfor the purpose of identifying the appearance of ulcers. Forefoot comprised zone I-IV and VIII, midfoot comprisedV and VI, hindfoot comprised zone VII. Neuropathy was diagnosed by clinical examination as well asby Semmes-Weinstein monofilament test. Ischemia was identified by the colour, hair distribution, temperature, distal pulses and hand held Doppler. Duplex scan was not done routinely.

Initially all the patients underwent regular dressings with proper wound care by wound debridement as well as shaving of hyperkeratotic tissue. The dressing protocol was chlorhexidine scrub wash followed by wet dressing soaked in povidone iodine and normal saline. In some cases, collagen dust dressing was also used. The wound care was also provided by foot bath in luke warm water mixed with povidone iodine solution in case of grossly infected ulcers. Then vasodilators were used to improve the peripheral perfusion. Different drugs were prescribed in following dosages to all patients. Tab. Diosmin (450mg) in combination with Hesperidin $(50 \mathrm{mg}$ ) was given 12 hourly for 4 months; Tab. Cilostazol (100mg) was prescribed 12 hourly for 2 months. Tab. Pentoxifylline $(400 \mathrm{mg}$ ) was prescribed 12 hourly for 2 months simultaneously; Tab. Zinc $(10 \mathrm{mg})$ was given 12 hourly for 2 weeks. Besides, Tab. Aspirin plus clopidogrel combination was advised as single dose for life long after surgical intervention. Different surgical reconstructions like STSG, V-Y plasty, rotation flap, cross-leg flap, double opposing S-flap, reverse flow sural artery flap, medial planter artery flap, filleted toe flap and free flap were adopted in different cases. Follow up wasdonefor 3 to 36 months.

Data were collected through a preformed, semistructured, interview and observation based case record form. Data were recorded, compiled, edited and analyzed. The results were presented in tabular and figure form. As it was a descriptive type of observational study there was no scope of determination of $p$-value. Data analysis was done in form of mean $\pm \mathrm{SD}$, frequency and percentages with the help of statistical package of social science software (SPSS software, illinois, chicago) version 23. 


\section{Results}

A total of 249 patients were studied. Of them, 93 (37.34\%) and $85(34.13 \%)$ patients were from $41-50$ and 51-60 years age groups respectively. 33(13.25\%) and $27(10.84 \%)$ patients were from 61-70 years and d"40 years age groups respectively. Only $11(4.41 \%)$ patients belonged to $>70$ years age group. The oldest age was found to be 83 years and youngest was 27 (mean 50.6).

Table I. Distribution of patients according to age group $(\mathrm{N}=249)$

\begin{tabular}{lcc}
\hline Age group (in years) & $\begin{array}{c}\text { Frequency } \\
(\mathrm{n}=249)\end{array}$ & $\begin{array}{c}\text { Percentage } \\
(\%)\end{array}$ \\
\hline$\leq 40$ & 27 & 10.84 \\
$41-50$ & 93 & 37.34 \\
$51-60$ & 85 & 34.13 \\
$61-70$ & 33 & 13.25 \\
$>70$ & 11 & 4.41 \\
Mean age \pm SD (in years) & \multicolumn{2}{c}{$50.6 \pm 12$} \\
Age range(in years) & \multicolumn{2}{c}{$27-83$} \\
\hline
\end{tabular}

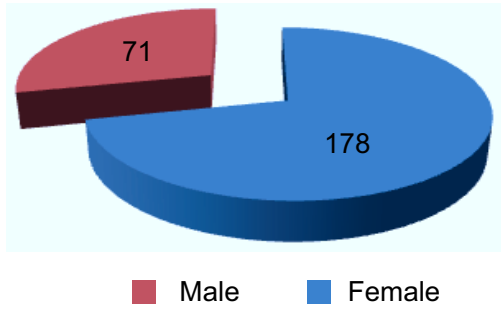

Figure 1. Distribution of patients according to sex $(N=249)$

Figure 1 shows that out of 249 patients, 178(71.49\%) and $71(28.51 \%)$ were male and female respectively. The male to female ratio was $2.5: 1$ that is the frequency of diabetic foot ulcer was 2.5 times higher in male than female.

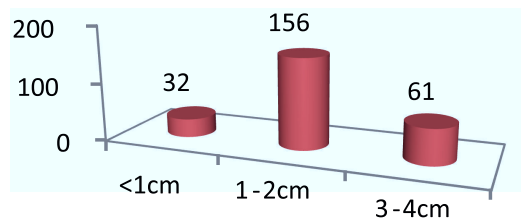

Figure 2. Distribution of patients according to ulcer size $(N=249)$
Figure 2 shows that out of 249 patients, the highest 156 (62.65\%) patients manifested the ulcer size between 1$2 \mathrm{~cm}$ which was subsequently followed by 61 (24.49\%) patients with ulcer size $3-4 \mathrm{~cm}$. Rest 32(12.85\%) patients had ulcer sized $<1 \mathrm{~cm}$. The mean ulcer size was $1.48 \mathrm{~cm}$ $(0.68-4.0 \mathrm{~cm})$.

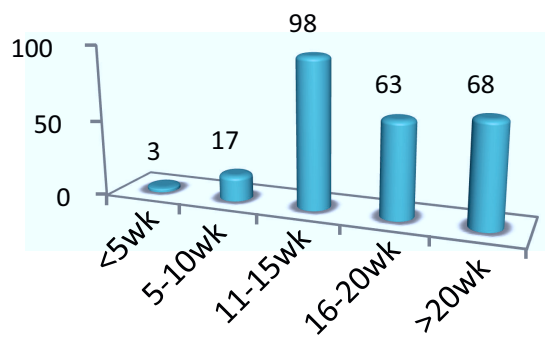

Figure 3. Distribution of patients according to duration of $D M(N=249)$

Figure 3 shows that among 249 patients, highest $98(39.35 \%)$ patients were suffering from diabetes mellitus for last $11-15$ weeks. $68(27.3 \%)$ and 63(25.3\%) patients were suffering from DM for $>20$ weeks and 16-20 weeks respectively (on the contrary, 17(6.82\%) and only $3(1.20 \%)$ patients had the history of DM for 5-10 weeks and $<5$ weeks respectively. The mean duration of DM was determined 15.4 \pm 9.9 weeks.

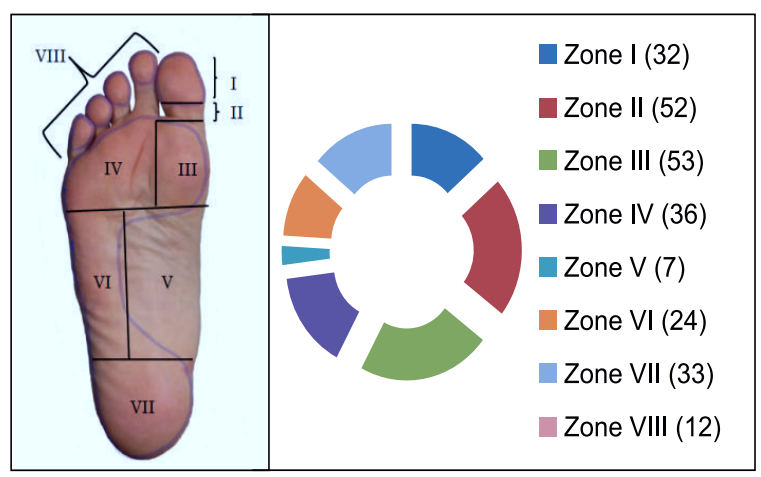

Figure 4. Distribution of ulcer according to the site of the sole $(N=249)$

Figure 4 shows that a topographic zone of ulcers, the maximum numbers of ulcers are seen in zone III- 53 $(21.28 \%)$ and minimum number is seen in zone $\mathrm{V}$ $7(2.8 \%)$. Zone I has $32(12.85 \%)$, zone II has 52 $(20.88 \%)$, zone IV has $36(14.45 \%)$, zone VI has 24 (9.6\%), zone VII has 33 (13.25\%) and zone VIII has 12 $(4.8 \%)$ ulcers. 
Table II. Distribution of patients according to ulcer criteria $(\mathrm{N}=249)$

\begin{tabular}{lc}
\hline Ulcer Criteria $(\mathrm{N}=249)$ & Values \\
\hline Ulcer size (Mean \pm SD) & $1.48(0.68-4.0)$
\end{tabular}

\section{Site of ulcer}

Fore foot

$186(74.69 \%)$

Mid foot

$33(13.25 \%)$

Hind foot

$30(12.04 \%)$

\section{Surface of ulcer}

Sole(wt bearing area)

$190(76.30 \%)$

Sole (non wt bearing)

$59(23.69 \%)$

\section{Duration of ulcer}

$\begin{array}{lc}3-4 \text { month } & 144(57.83 \%) \\ 4-6 \text { months } & 59(23.69 \%) \\ 6-12 \text { months } & 31(12.45 \%) \\ >12 \text { months } & 15(6.02 \%)\end{array}$

Type of ulcer

\section{Neuropathic}

Neuroischemic

Ischemic

Non-neuropathic, non-ischemic 12 (4.8\%)

\section{Wagner's grade of ulcer}

Grade-1

Grade-2

G1rade-3
$97(38.95 \%)$

$113(45.38 \%)$

$182(73.09 \%)$

$51(20.48 \%)$

$4(1.6 \%)$

$39(15.66 \%)$
Among 249 patients, $186(74.69 \%)$ had ulcer in the forefoot, $63(25.30 \%)$ presented with ulcer in the midfoot and hindfoot of the sole. In 190(76.30\%) cases ulcer was in the weight bearing area and in 59(23.69\%) cases it was in the non-weight bearing area. The duration of ulcer revealed that $144(57.83 \%)$ and $59(23.69 \%)$ patients belonged to the groups of 3-4 month and 4-6 months respectively. The type of ulcer showed that 182(73.09\%), 51(20.48\%), 12(4.81\%) and 4(1.6\%) patients were suffering from neuropathic, neuroischemic, non-neuropathic, non-ischemic and ischemic ulcer respectively. The Wagner's grade of ulcer revealed that Grade-2 were the highest $113(45.38 \%)$ which was subsequently followed by Grade-1 97(38.95\%), rest 39(15.66\%) were Grade-3. Grade 4 and 5 were excluded from this study.
Table III. Distribution of patients according to outcome ( $\mathrm{N}=249)$

\begin{tabular}{lcc}
\hline Outcome & $\begin{array}{c}\text { Frequency } \\
(\mathrm{n}=249)\end{array}$ & $\begin{array}{c}\text { Percentage } \\
(\%)\end{array}$ \\
\hline Successfully treated & 194 & $77.91 \%$ \\
Secondary procedure & 55 & $22.08 \%$ \\
a) Flap revision & 34 & $61.81 \%$ \\
b) Debridement \& STSG & 21 & $38.18 \%$ \\
\hline
\end{tabular}

Table III represents that out of 249 patients undergoing both vasodilators and surgical reconstructions, 194(77.91\%) had uneventful outcome. Rest 55(22.08\%) required secondary procedure. Among these 55 cases, $34(61.81 \%)$ required flap revision, $21(38.18 \%)$ required debridement \& STSG. The follow up was given from 3 months to 36 months.

Table IV. Distribution of patients according to successful surgical reconstructions $(\mathrm{N}=194)$

\begin{tabular}{lcc}
\hline Surgical reconstructions & $\begin{array}{c}\text { Frequency } \\
(\mathrm{n}=194)\end{array}$ & $\begin{array}{c}\text { Percentage } \\
(\%)\end{array}$ \\
\hline Split thickness & & \\
skin grafts & 98 & 50.51 \\
Local flaps & 56 & 28.86 \\
Regional flaps & 32 & 16.49 \\
Distal flaps & 08 & 4.12 \\
\hline
\end{tabular}

Out of 194 patients who were successfully treated in the first attempt without any secondary procedure, it was seen that, 98(50.51\%) had STSG, 56(28.86\%) had local flap reconstruction, 32(16.49) required regional flaps and rest $8(4.12 \%)$ cases required distal flaps for the coverage of the wounds. 55 patients required secondary procedures due to post operative complications.

\section{Discussion}

Bangladesh Institute of Research and Rehabilitation in Diabetes, Endocrine and Metabolic Disorders (BIRDEM), a central referral hospital in Dhaka city, provides basic diabetes care to a large number of diabetic populations. The total number of registered patients in BIRDEM is $>3,20,000$ and daily turnover is around $2500 .{ }^{11}$ A retrospective cohort study from 1980 to 1995 among patients in BIRDEM showed a $2.8 \%$ prevalence of diabetic foot ulcer. ${ }^{12}$ 
According to Professor Karell Baker (Chairman InternationalWorking Group of Diabetic Foot) only $14 \%$ of doctorstreating diabetics ask patients to take off the shoes andexamine their feet. ${ }^{10}$ A study stated that $<20 \%$ of diabeticpatients are given proper foot examination by primary careproviders. ${ }^{13}$

This study observed the outcome of combination approach by vasodilators and different modalities of reconstructive surgery. The outcome profile revealed that $77.91 \%$ patients had good outcome whereas $22.08 \%$ patients required further interventions. The reason for that was mostly uncontrolled blood sugar with $\mathrm{HbA}_{1} \mathrm{C}>9$, multi drug resistant bacterial infection and persistent skeletal deformity. The significant successful surgical reconstruction with long term follow up was may be due to appropriate use of different vasodilators.

Our study showed that the mean age of the sufferer was $50.6 \pm 12$ years (age range: $27-83$ years). Our study results are also consistent with other countries scenario with low per capita income. ${ }^{15}$

The sex distribution revealed $71.49 \%$ of total sample size was male and $28.51 \%$ of same population was female. The male to female ratio was $2.5: 1$ which is in agreement with other previous studies. ${ }^{16-17}$ Smoking status may be an attributable factor in this regard which is absolutely absent in female in our perspective. The nicotine and other toxic substances of cigarette are responsible for vascular wall change that contributes to PAD which is highly prevalent in DM. Besides, vasa nervorum becomes weaker in those patients that aggravate diabetic neuropathy leading to DFU. ${ }^{18}$ According to our social practice; care of foot is less practiced that is also attributable to DFU. As male are mostly earning members of family they have to go outside regularly for job. But unfortunately negligence of foot compels them to overlook the minor injuries that may result in a grave condition in future.

This study showed an interesting fact that a large number of ulcers were found in zone II (proximal phalanx of great toe) which is a non weight bearing area of the foot. The second most common site was zone III which was the ball of the great toe. $190(76.30 \%)$ ulcers were seen on the weight bearing area of the sole of the foot, whereas $59(23.69 \%)$ ulcers were seen on the non-weight bearing area. This coincides with the fact that intrinsic foot muscle deterioration and limited ankle dorsiflexion were associated with the severity of metatarsophalangeal joint deformity in diabetic foot. ${ }^{19}$

In this study, relatively longer duration of DM with DFU at first presentation to the hospital was observed which was in line with other studies of similar country profile like us. ${ }^{20}$

There is a common perception in our country not to save any pocket money for health disaster in every family. For that reason, health consciousness and health education status are extremely poor in our perspective. The low socioeconomic status is the root cause of this condition similar factor is also claimed in a previous study of a similar profile country study. ${ }^{21}$

This study revealed the Wagner's grade of ulcer Grade2 was in $45.38 \%$ cases whereas Grade-I was in $38.95 \%$ cases. This status helps us to implement both pharmacological and surgical approach as this is the preliminary factor to have the patients in early Wagner grades for foot salvage approach. In the study by Kenneth EzenwaAmaefule and his colleagues, maximum patients were from Wagner grade 4 and 5 that compelled them to choose amputation. ${ }^{22}$

In this study, the vasodilators like Cilostazol, Pentoxifylline, Xinc, combination of Hesperidine and Diosmin as well as antiplatelet drugs like Aspirin and Clopidogrel were used to treat the ischemic episodes of diabetic foot ulcers and it was observed that $77.91 \%$ patients showed remarkable outcome without complications. Even $22.08 \%$ patients who required further intervention also showed better results. The combination approach of vasodilators and surgical reconstruction in case of management of diabetic foot ulcer is gaining popularity day by day for its excellent effectiveness and patients' compliance.

Limitation of this study was that Duplex scan of thelower limb vessels was not donein all patients as it was expensive. We did not perform sensory assessment of the patients according to the site and severity. So we were not able to associate the clinical profile with outcome of diabetic foot problem.

\section{Conclusion}

Chronic non-healing ulcer in diabetes mellitus can be effectively treated by combination therapy of vasodilators and different modalities of surgical reconstructions. This study recommends doing vascular 
assessment and neurological assessment of lower extremities of all diabetic foot patients as that will make this type of study more precise and indicate the justification of using vasodilators instead of empirical use.

Conflict of interest: Nothing to declare.

\section{References}

1. Uccioli L, Meloni M, Izzo V. Limb Salvage in Diabetic Patients: The Italian Experience. Clin Res Foot Ankle 2014;S3: S3-007.

2. International Diabetes Federation e-atlas of diabetes. 5th ed., http://www.idf.org/diabetesatlas; 2011 [accessed November 2017].

3. International Working Group on the Diabetic Foot. International Consensus on the Diabetic Foot and Practical Guidelines on the Management and the Prevention of the Diabetic Foot. Amsterdam, the Netherlands, 2011.

4. Pecoraro R, Reiber G, Burgess E. Pathways to diabetic limb amputation: a basis for prevention. Diabetes Care 1990;13: $513 \mathrm{e} 21$.

5. American Diabetes Association. Standards of medical care in diabetes-2013. Diabetes Care 2013; 36:S11-S66.

6. Crawford F, Inkster M, Kleijnen J, Fahey T. Predicting foot ulcers in patients with diabetes: a systematic review and metaanalysis. Q J Med 2007; 100:65-86.

7. Ebskov B, Ebskov L (1996) Major lower limb amputation in diabetic patients: development during 1982 to 1993. Diabetologia 39: 1607-10.

8. Lombardo FL, Maggini M, De Bellis A, Seghieri G, Anichini R. Lower extremity amputations in persons with and without diabetes in Italy: Diabetologia. 2014; 2001-2010.

9. Prompers L, Huijberts M, Apelqvist J, Jude E, Piaggesi A, Bakker K, et al. High prevalence of ischaemia, infection and serious comorbidity in patients with diabetic foot disease in Europe. Baseline results from the Eurodiale study. Diabetologia 2007; 50:18e25.
10. Saleh F, Ahmed KR, Rashid IB, Akter F, Hannan JMA, Ali L, Rahman M, Mannan S, Thilsted S. Evaluation of the levels of knowledge, attitude and practices of Bangladeshi Type 2 Diabetic subjects. DiabEndocr J 2005; 33(1): 24-27.

11. Samira HH, Sayeed MA, Lahiry S, L Ali. Burden of diabetic foot ulcer. DiabEndocr J 2006; 34(suppl 1): 11-12.

12. Boulton AJ, Meneses P, Ennis WJ. Diabetic foot ulcers: A frame work for prevention and care. Wound repair and regeneration 1999; 7: 7-16

13. Brand FN, Abbott RD, Kannel WB. Diabetes, intermittent claudication, and risk of cardiovascular events. The Framingham Study. Diabetes 1989; 38:504-9.

14. Cawich SO, Islam S, Hariharan S, Harnarayan P, Budhooram $\mathrm{S}$, Ramsewak S, et al. The economic impact of hospitalization for diabetic foot infections in a Caribbean nation. Perm J 2014;18: e101 4.

15. Isiguzo CM, Jac Okereke C. Diabetic foot ulcers 12 months' prospective review of pattern of presentation at Enugu state university of technology teaching hospital, Parklane, Enugu: A basis for diabetic foot clinic? Niger J Med 2015; 24: $125-30$.

16. Hjelm K, Beebwa E. The influence of beliefs about health and illness on foot care in ugandan persons with diabetic foot ulcers. Open Nurs J 2013; 7:123-32.

17. Venermo M, Manderbacka K, Ikonen T, Keskimäki I, Winell K, Sund R. Amputations and socioeconomic position among persons with diabetes mellitus, a population based register study. BMJ Open 2013;3. pii: e002395.

18. Cheuy VA, Hastings MK, Commean PK, Mueller MJ. Muscle and Joint Factors Associated With Forefoot Deformity in the Diabetic Neuropathic Foot. Foot \& ankle international. 2016;37:514-21.

19. Doumi A. Diabetic septic foot in El Obeid, Western Sudan. Sudan J Med Sci2007; 2:119-21.

20. Famuyiwa OO, Edozien EM, Ukoli CO. Social, cultural and economic factors in the management of diabetes mellitus in Nigeria. Afr J Med MedSci1985; 14:145-54.

21. Amaefule KE, Okpe IO, Dahiru IL, Aruna AA. Reducing diabetes-related major limb amputations: A plea for a multidisciplinary team approach. Sub-Saharan Afr J Med 2016; 3:102-5. 